\title{
Serendipity and targeted hope
}

\author{
by Paul McKellips
}

It was only seven months after John Glenn became the first American to orbit the Earth aboard Friendship 7. The US was already a full year behind the Soviet Union's startling accomplishment of putting the world's first human, Yuri Gagarin, into space. No space walks had ever taken place. No dockings of space vehicles had ever been attempted. A lunar module had not been built. And the new metal alloys required to withstand re-entry into the Earth's atmosphere had not even been invented.

Nevertheless, on 12 September 1962 , one man spoke the words that challenged a nation of brilliant scientists to think the unthinkable and accomplish the impossible.

"We choose to go to the moon. We choose to go to the moon in this decade and do the other things, not because they are easy, but because they are hard, because that goal will serve to organize and measure the best of our energies and skills, because that challenge is one that we are willing to accept, one we are unwilling to postpone, and one which we intend to win, and the others, too."

President John F. Kennedy laid out a vision-an unprecedented goal-and he arbitrarily put a seven-year timeline in place.

What JFK didn't say that day at Rice University is just as important. He didn't say, "Let's just get into space and see what happens." He didn't say, "Let's go to the moon someday when we can."

The first great step in this giant leap for mankind started when one man verbalized America's choice to go to the moon. Kennedy knew that the power of this publicly stated goal would establish a framework, a comprehensive and systematic structure that would marshal all the energy and skill the scientific community had to offer. The choice became a decision; the decision became a

McKellips is Executive Vice President of the Foundation for Biomedical Research in Washington, DC. national goal; and the statement of that goal established the organizational framework.

The second great step Kennedy made that day was a bridge to national buy-in. Going to the moon was a challenge the entire country was asked to accept. The Apollo 11 crew of Michael Collins, Buzz Aldrin and Neil Armstrong flew the mission, but an entire country and much of the world went along for the ride as well.

\section{Hope is the fuel that must fill the biomedical research engine every day.}

It was not an easy journey. In January 1967, just thirty months shy of the successful moon landing, the three astronauts of Apollo 1 were killed in a launch-pad test. The experiment failed. The science and engineering were faulty. The data were imperfect. And three brave astronauts died in a terrifying blaze. Surely, our "choice" to go to the moonnot because it was easy, but because it was hard-was being questioned and secondguessed. The world was filling with new skeptics and old naysayers. Even scientists were dealing with self-doubt. And the voice of the original vision had been silenced in Dallas almost four years earlier.

So why didn't the challenge fail? Why didn't the skeptics win? Why didn't NASA backtrack and formulate a new goal, a more reasonable target, with a more achievable outcome?

Because targeted hope had become part of the collective human fabric through the moon mission. The willingness to pursue the unimaginable and achieve the impossible was more powerful than experiments gone bad or scientific discovery that wasn't quite ready for prime time.

In an effort to achieve the unthinkable, science became vulnerable. Science was willing to fall short with full transparency, to fail in the public spotlight of scrutiny and to endure the criticism of skeptics.

Through the "space race," we accidentally discovered thousands of pieces of technology that are still relevant in our modern lives today. Serendipity has a way of multiplying the benefits of research tenfold.

But the greatest thing we discovered on the way to the moon was hope. When choice became a decision and decision became a challenge, that challenge gave us all hope.

Make no mistake about it: the entire world is hoping for cures to cancer, heart disease, Alzheimer's and hundreds of other maladies. When President Nixon launched the "War on Cancer," he famously cautioned against raising false hopes. When the human genome was finally mapped, some within the biomedical research community famously over-promised on its deliverables; now, hope is seldom mentioned for fear of creating unrealistic expectations.

Some might argue that 'hope' is not a scientific term. But I embrace hope just as much as serendipity and blind luck. Hope is the fuel that must fill the biomedical research engine every day.

Without hope, the people perish. Without hope, funding is reduced, transportation is idled and extremists have a platform.

We choose to find cures for cancer, breakthroughs for Alzheimer's and discoveries for cystic fibrosis because hope is the fuel that moved us to become physicians, nurses, professors, scientists, researchers, veterinarians, lab animal supervisors, veterinary technicians and animal care specialists.

Regardless of failed experiments, skeptics and naysayers, we choose to find the keys to human and animal health-not because this is easy to do, but because it is hard.

Most of all, we choose to hold on to hope. Discovery of cures is the challenge we are willing to accept, one we are unwilling to postpone and one we intend to win. 